\title{
A Study on the liquefaction risk in seismic design of foundations
}

\author{
Saeid Ardeshiri-Lajimi ${ }^{1}$, Mahmoud Yazdani $^{2}$ and Arya Assadi-Langroudi ${ }^{* 3 a}$
}

\author{
${ }^{1} M S c$ Graduate, School of Civil and Environmental Engineering, Tarbiat Modares University, \\ Iran \\ ${ }^{2}$ Associate Professor, School of Civil and Environmental Engineering, Tarbiat \\ Modares University, Iran \\ ${ }^{3}$ Lecturer, School of Architecture, Computing and Engineering, University of East London, England, UK
}

\begin{abstract}
A fully coupled non-linear effective stress response finite difference (FD) model is built to survey the counter-intuitive recent findings on the reliance of pore water pressure ratio on foundation contact pressure. Two alternative design scenarios for a benchmark problem are explored and contrasted in the light of construction emission rates using the EFFC-DFI methodology. A strain-hardening effective stress plasticity model is adopted to simulate the dynamic loading. A combination of input motions, contact pressure, initial vertical total pressure and distance to foundation centreline are employed, as model variables, to further investigate the control of permanent and variable actions on the residual pore pressure ratio. The model is verified against the Ghosh and Madabhushi high acceleration field test database. The outputs of this work is aimed to improve the current computer-aided seismic foundation design that relies on ground's packing state and consistency. The results confirm that on seismic excitation of shallow foundations, the likelihood of effective stress loss is greater in deeper depths and across free field. For the benchmark problem, adopting a shallow foundation system instead of piled foundation benefitted in a $75 \%$ less emission rate, a marked proportion of which is owed to reduced materials and haulage carbon cost.
\end{abstract}

Keywords: Liquefaction; dynamic; Finite Difference; effective stress; surcharge; non-linear; carbon

\section{Introduction}

Liquefaction in the context of high $-\mathrm{r}_{\mathrm{u}}>60 \%$ after Seed (1987) - pore water pressure induced volumetric deformations is likely to occur in particulate materials including ground rock and mining wastes (James et al., 2011), clean sands and silty sands. Implications of liquefaction in urban settings are floatation - predominantly in underground structures (Chian et al. (2014); Sawicki and Mierczyński (2015)) and excessive settlements (Romeo et al. 2015). Seismic actions are often sourced from the inertia loads in onshore wind turbines in the event of emergency stop, traffic loads in maglevs (Wichtmann et al., 2004) as well as high speed rails (Naeini and Gholampoor, 2014). Wind turbines, a source of dynamic actions, are attracting increasing interest in the light of legally binding greenhouse gas emissions plans. As an example, the development of onshore wind farms in the UK is expected to continue to year 2020 with an aim to supply over 10 per cent of electricity annually (Simpson, 2013). Planned and built turbines are widely distributed across the country, mostly coastlines and quaysides which are covered with saturated sand alluvium superficial drifts, a ground type which can potentially experience liquefaction under transient loads from turbines. For the renewable energy infrastructure together with the newly planned rail transport infrastructure to be developed in the years to come, the ground engineering practice needs to seek sustainable solutions to deliver a safe design while contributing to emissions reduction pledges. One simple strategy is to explore the opportunity of using gravity bases rather than deep foundations (and stone columns). To do so, revisiting the risk assessment methods and enhancing our understanding of controlling factors of liquefaction is an ambitious, yet promising aim.

*Corresponding author, Lecturer, E-mail: A.AssadiLangroudi@uel.ac.uk 
Cyclic shearing of saturated sands results in grain rearrangement and irrecoverable volume contraction under constant confining stress, which leads to pore pressure buildup and ultimately a loss in shear strength. Recent works suggest a reverse relationship between permanent overhead loads and liquefaction induced subsidence (Bertalot and Brennan, 2015). With pore pressure building up, the effective stress acting on grains tends to zero, while pore pressure tends to the initial confining pressure. A variation in the stress state affects both the strength and stiffness of soil. Particularly at large strains, $\mathrm{K}$ and $\mathrm{G}$ decrease and as such modulus reduction $\mathrm{G} / \mathrm{G}_{\max }$ and damping $\mathrm{D} \%$ factors are best to be incorporated in design in nonlinear frameworks. Nonlinear soil response models have been practiced since the mid-1970s and benefitted in bringing in the pore pressure development into analysis. Adoption of nonlinear analysis is in particular useful (Wang et al., 2013) when soft soils are assessed under seismic excitation. A number of commercial computer codes take into account soil nonlinearities, although these generally lack in not employing advance constitutive models, including isotropickinematic hardening constitutive, hypo-plastic, or incrementally nonlinear models. Good recent contributions include the works of Abate et al. (2007) and Abate et al. (2008), in which a simple isotropic-kinematic hardening constitutive model was embedded into a commercial code and practical implications were evaluated thereafter- see Abate et al. (2010) and Maugeri et al. (2013). The advanced constitutive formulations, however, from a practical standpoint, often lack in being couched in part due to their association with specific laboratory tests. Finn model is one simple well-established formulation that incorporates irrecoverable volume-strains $\left(\Delta \varepsilon_{v d}\right)$ versus cyclic shear-strain amplitude equations into the M-C failure criterion (Martin et al., 1975; Wang et al., 2013).

Identification of the potential of liquefaction and prediction of resulting ground displacements have long been subjects of much research with a suite of shortfalls remained yet to be filled. Disputed matters include the confining stress threshold to which a soil may liquefy, and hence the cost of employing an appropriate amelioration strategy to that critical depth. The soil's liquefying depth is often reported as low as 15m (Steedman et al., 2000; Youd et al., 2001), making piled foundation a viable structural solution; particularly in regions of moderate to high seismicity. A better understanding of the liquefaction mechanism can contribute to the sustainability of ground works and specifically in the adoption of foundation type. For a benchmark problem, dynamic pore pressure calculations is performed employing Finn model within 10 scenarios including 5 acceleration time histories and 2 action combinations (i.e. permanent and variable loads). The performance of the employed plasticity model is examined through comparing measured and predicted pore pressure values gained by a published high acceleration test as a measure of liquefaction risk.

\section{Benchmark Problem}

The study area is a wide lowland, with moderate seismicity (design peak ground acceleration of $0.3 \mathrm{~g}$ as recommended by national regulations) along the Caspian Sea coast comprised of deep profiles of clayey silty sand drifts, with water standing at $1 \mathrm{mbgl}$. Ground conditions and characteristic material properties are summarized in Table 1 and Fig. 1.

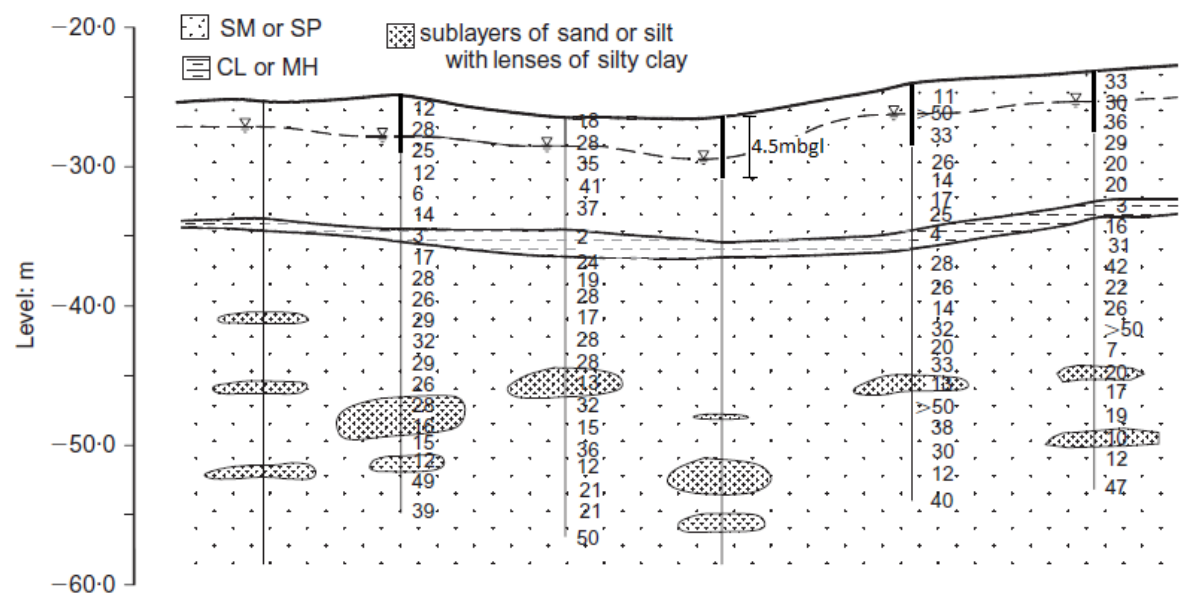

Fig. 1 Blow count SPT profile on the geological conceptual model: reproduction of an earlier ground 
investigation in the same area in Majidi et al. (2007)

Table 1. Ground conditions: $0 \mathrm{mAOD}-8 \mathrm{mbgl}^{\dagger}$

\begin{tabular}{|l|l|l|l|l|}
\hline & \multicolumn{1}{|c|}{ Upper sand drift } & \multicolumn{1}{|c|}{$\begin{array}{c}\text { Middle sandy } \\
\text { clayey silt drift }\end{array}$} & \multicolumn{1}{|c|}{$\begin{array}{c}\text { Upper sand drift } \\
\text { (Late Holocene) }^{3}\end{array}$} & \multicolumn{1}{|c|}{$\begin{array}{c}\text { Characteristic } \\
\text { parameters }^{\dagger}\end{array}$} \\
\hline $\mathrm{D}>2 \mathrm{~mm}: \%$ & $0-5$ & $0-1$ & $0-5$ & $0-2$ \\
\hline $\mathrm{D}: 63 \mu \mathrm{m}-2 \mathrm{~mm}: \%$ & $60-96$ & $2-49$ & $20-65$ & $10-55$ \\
\hline $\mathrm{D}<63 \mu \mathrm{m}: \%$ & $0-40$ & $51-98$ & $30-80$ & $25-60$ \\
\hline $\mathrm{D}_{\text {median }}: \mu \mathrm{m}$ & $110-270$ & $1.5-60$ & - & $150-300$ \\
\hline $\mathrm{W}: \%$ & $6.0-50.0$ & $30-92$ & $25-80$ & $25-60$ \\
\hline$\gamma: \mathrm{kN} / \mathrm{m}^{3}$ & $17.5-18.5$ & $15.5-17.5$ & $15.5-18.5$ & $18.0-20.0$ \\
\hline $\mathrm{e}$ & $0.5-1.7$ & $0.8-2.0$ & $0.7-1.9$ & $1.1-1.8$ \\
\hline $\mathrm{N}_{(60)}$ & $>2$ & $5-35$ & $2-30$ & 25 \\
\hline $\mathrm{C}^{\prime}: \mathrm{kPa}$ & $0.01-0.03$ & $0.05-0.25$ & - & 0.1 \\
\hline$\varnothing^{\prime}:{ }^{\circ}$ & $25-35$ & $15-25$ & - & 30 \\
\hline $\mathrm{E}_{\mathrm{s}}: \mathrm{kN} / \mathrm{m}^{2}$ & - & - & - & 15,000 \\
\hline $\mathrm{E}_{\mathrm{d}}: \mathrm{kN} / \mathrm{m}^{2}$ & - & - & - & 20,000 \\
\hline 0 & - & - & - & 0.3 \\
\hline $\mathrm{K}: \mathrm{m} / \mathrm{s}$ & - & - & - & $1 \mathrm{E}-06$ \\
\hline
\end{tabular}

1,2 consistent with figures in Hashemi et al. (2013); ${ }^{3}$ also see Hashemi et al. (2014)

${ }^{\dagger}$ Ground properties used as input model parameters are listed in Column 5 'Characteristic parameters' (upper drift)

For the purpose of analysis, five acceleration time histories were adopted (as detailed in Section 3). Baseline-corrected response spectra graphs are illustrated in Fig. 2.

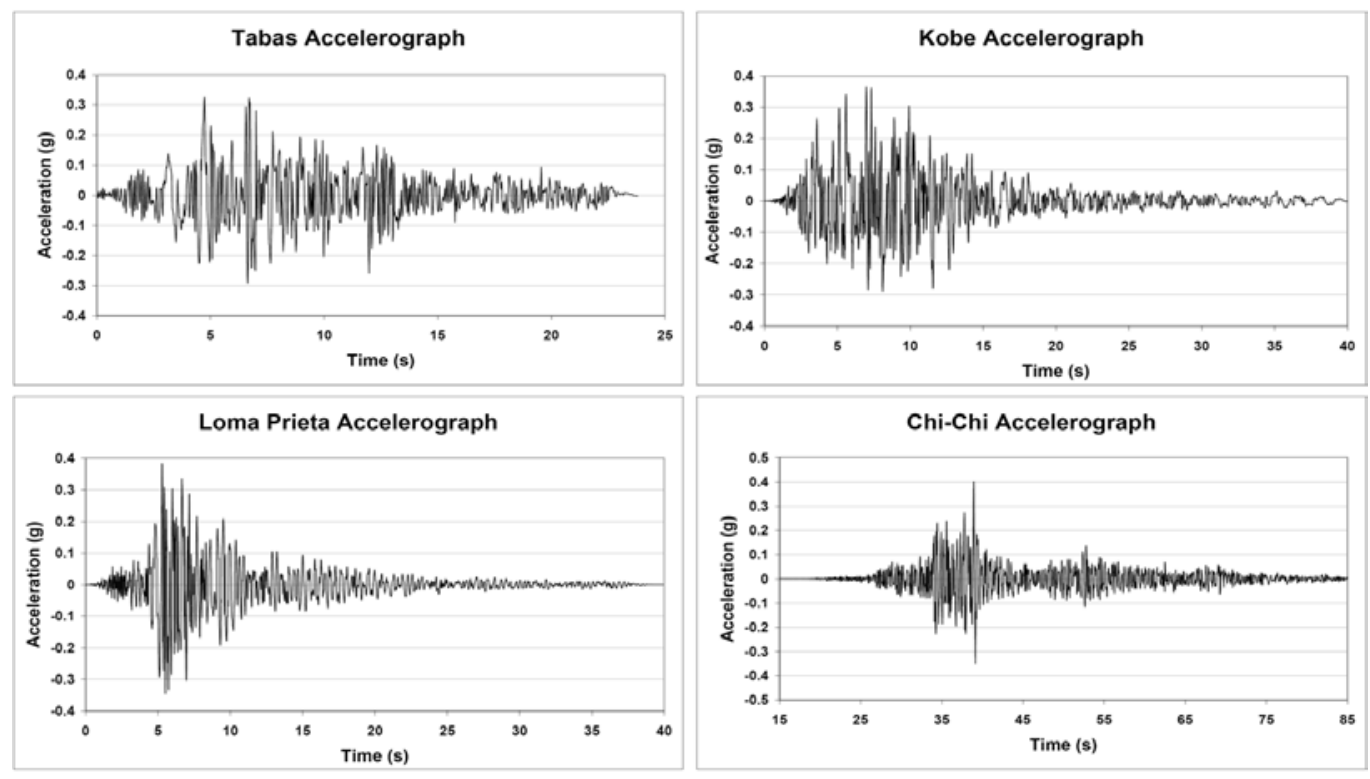

Fig. 2 Baseline-corrected acceleration series

\section{Model development}

\subsection{Soil, Structure, and Soil-Structure Interface}

The benchmark problem is modelled using the computer code FLAC - Fast Lagrangian Analysis of Continua (Fig. 3). A $5.5 m \times 2.0 m$ beam element of $1.5 \mathrm{E}+8 \mathrm{kN} \cdot \mathrm{m}^{2}$ bending stiffness (i.e. linear elastic) is used to model the mat foundation under plane strain conditions, which supports the 4-storey super structure with a contact pressure of $40 \mathrm{kPa}$. The non-linear response of soil is simulated using the plastic Mohr-Coulomb constitutive relationship, and 4-noded 1-to-2m width soil elements. Pore water pressure buildup and dissipation are simulated using the Finn model. Maximum element size is set at $2 \mathrm{~m}$ (i.e. 
approximately smaller than one-tenth to one-eighth of the wavelength associated with the highest frequency of input wave - see Kuhlemeyer and Lysmer (1973)). The soil-structure interface is modelled using a linear spring-slider system with M-C failure shear strength criterion as 2D plain strain elements of equal normal and tangential stiffness (set to equivalent stiffness of adjoining soil element in the normal direction - see Eq. 1).

$K_{n(\max )}=K_{s(\max )}=10 \times \operatorname{Max} \frac{K+\frac{4 G}{3}}{\Delta Z_{\min }}$

where $\Delta Z_{\min }$ is the smallest dimension of an adjoining zone in the normal direction, $K$ is the bulk modulus of soil and $G$ is the shear modulus of soil.

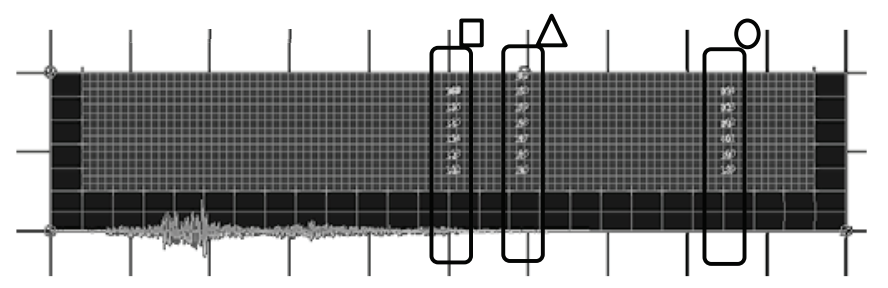

Centre of the loaded area

$\triangle$ On the boundary of the loaded area

O At a distance from the loaded area

(a)

Fig. 3(a) Model layout: free-field conditions applying to side boundaries; 3(b) Artistic view of the superstructure on piles (3D scheme)

\subsection{Soil constitutive model}

The elastic-perfectly plastic Mohr-Coulomb (M-C) constitutive model is adopted to simulate the nonlinear soil behavior under monotonic loading (i.e. gravity) conditions. The M-C model used is based on plane strain conditions and effective stresses. For the subsequent dynamic analysis however, in order to take into account the broadly-agreed increase in pore water pressure on mechanical dynamic loading, the Finn effective stress plasticity strain-hardening with non-associated flow rule model (i.e. formulations embedded in FLAC 2D through the User-Defined Model feature) is adopted. The model is credible for fine granular saturated geomaterials with a relative density of $<80 \%$. A hyperbolic relationship is assumed between shear stress and strain, using a flow rule based on the stress ratio $(\eta=$ $\left.\tau / \sigma^{\prime}\right)$, where $\tau$ and $\sigma^{\prime}$ are the shear and normal effective stresses on the plane of maximum shear stress, respectively. The model considers the developed pore pressure per cycle as a function of the plastic volumetric strain, rebound soil modulus and pore fluid stiffness. A detailed account of the model calibration against laboratory tests is given in Section 3.4.

The elastic component of soil response is set to be isotropic and characterized by $G^{E}$ (shear modulus) and $B^{E}$ (bulk modulus) as detailed in Equation 2.

$G^{E}=K_{G}^{E} \cdot P_{a} \cdot\left(\frac{\sigma^{\prime}}{P_{a}}\right)^{n e}$

$B^{E}=\alpha \cdot G^{E}$

where

$$
K_{G}^{E}=\frac{\Delta P_{f}}{\Delta \varepsilon_{v}}=\frac{\Delta P_{f}}{8.7 N_{160}{ }^{-1.25} \cdot\left(\gamma-\frac{0.4}{8.7 N_{160}{ }^{-1.25}} \varepsilon_{v}\right)+\frac{C_{3} \varepsilon_{v}^{2}}{\gamma+C_{4} \varepsilon_{v}}}
$$

Where $\Delta \varepsilon_{v}$ is the increment of volume decrease, $C_{3}$ and $C_{4}$ are constant values and $\Delta P_{f}$ is the total pressure.

Upon the first time shear loading, yield surface forms as a function of the current stress state. With 
increasing shear stress, the yield surface expands (strain-hardening), inducing plastic shear and volumetric strains. Equation 4 shows the relevance of plastic shear strain increment $d \gamma^{p}$, with variation in shear stress ratio $d \eta$.

$d \gamma^{p}=\frac{1}{G^{p} / \sigma^{\prime}} \cdot d \eta$

in which the plastic shear modulus, $G^{p}$, is a hyperbolic function of stress ratio $\eta=\tau / \sigma^{\prime}$ and $\gamma^{p}$,

$G^{p}=G_{i}^{p} \cdot\left(1-\frac{\eta}{\eta_{f}} R_{f}\right)^{2}$

and $R_{f}$ is the failure ratio of a value 0.7 to 0.98 in order, inversely proportional to the relative density, and $\eta_{f}$ is the stress ratio at failure.

The associated increment of plastic volumetric strain, $d \varepsilon_{v}^{p}$, is expressed as a function of plastic shear strain increment, $d \gamma^{p}$, through the flow rule in Equation 6.

$d \varepsilon_{v}^{p}=\left(\sin \phi_{c v}-\frac{\tau}{\sigma^{\prime}}\right) \cdot d \gamma^{p}$

in which $\phi_{c v}$ is the critical state friction angle. Depending on the $\phi_{c v}$, plastic volumetric strain may be either contractive or dilative: for a stress ratio representing a friction angle less than $\phi_{c v}$, a contractive behavior could be expected, whereas for $\phi>\phi_{c v}$, soil tends to dilate.

\subsection{Model verification}

Numerical effective stress modelling needs to be verified experimentally using soil models, which are representative of field stress state. To replicate the ground stress conditions at laboratory scale, base motion can be simulated on prototypes under a $>1 \mathrm{~g}$ acceleration field. The measured timed-trend of excess pore water pressure - by the high acceleration field test - in Ghosh and Madabhushi (2004) is compared with the predicted figures gained by the simulated test model to ensure the consistency. Measured and predicted figures are presented in Fig. 4 for a saturated dense sand soil at the depth of $4.5 \mathrm{mbgl}$, subjected to an acceleration field of $50 \mathrm{~g}$ under a $150 \mathrm{kPa}$ surcharge.

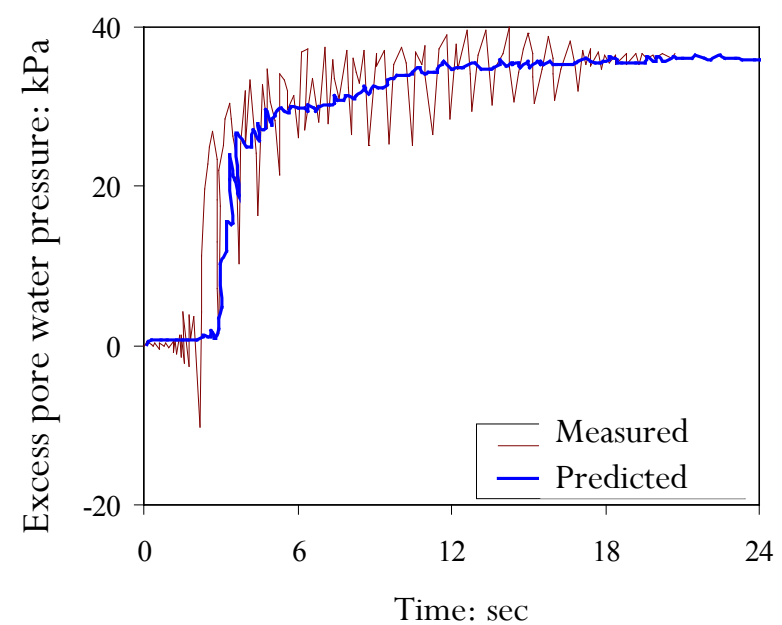

Fig. 4 FLAC predicted excess pore pressures versus exp̣eriiiinienititally measured figures after cyclic shearing simulation in Ghosh and Madabhushi (2004)

\section{Results and Discussion}

Each model is subjected to five input ground motions, including a sequence of scaled versions of components of the Loma Prieta (1989), Tabas (1978), Northridge (1994), Chi-Chi (1999), and Kobe (1995).

For the impact of surcharge on liquefaction to be determined, the risk is once measured against depth (at 6 points below ground level) at varied distances from the loaded area, and once for varied surcharge values. To measure the risk, the pore pressure ratio $r_{u}$ (i.e. normalized excess pore pressure against the initial effective overburden stress) of 0.7 is set threshold beyond which liquefaction is probable. $r_{u}$ is 
plotted against depth beneath the centerline of the loaded area, beneath the boundaries of the loaded area, and at a distance from the loaded area. Frequency cut-off is set at $5 \mathrm{~Hz}$ (i.e. low pass filter) for a $5 \%$ damping ratio. Two load combinations are considered for each of the input time histories: unfactored permanent action $(\mathrm{G})$, and combined permanent $(\mathrm{G})$ and variable actions $(\mathrm{Q})$. Time histories of effective stress against depth under foundation centerline, foundation boundary and the free ground are captured for two load combinations are plotted in Fig. 5.
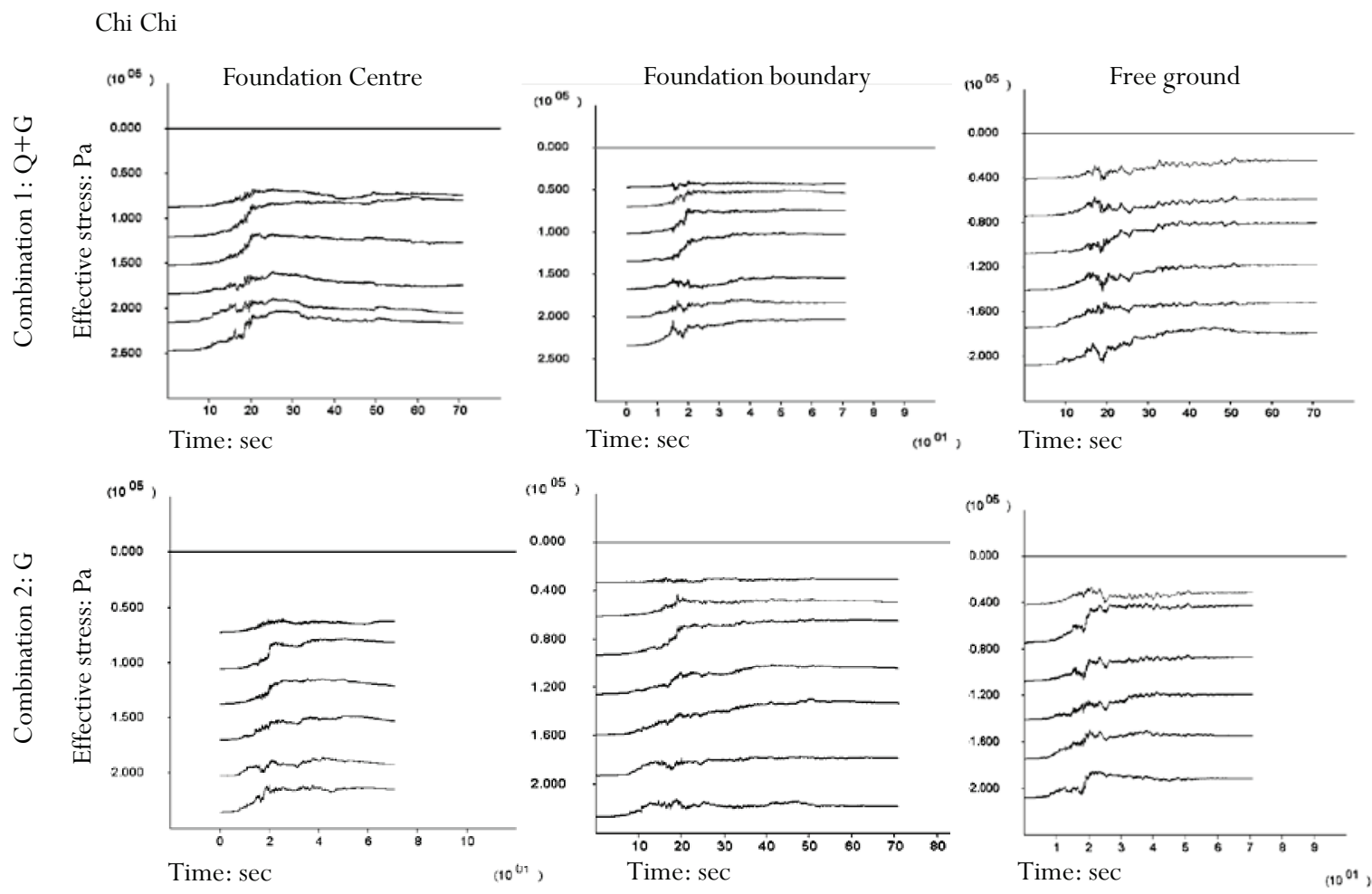

Fig. 5(a) Time history of effective stress - Chi Chi scenario
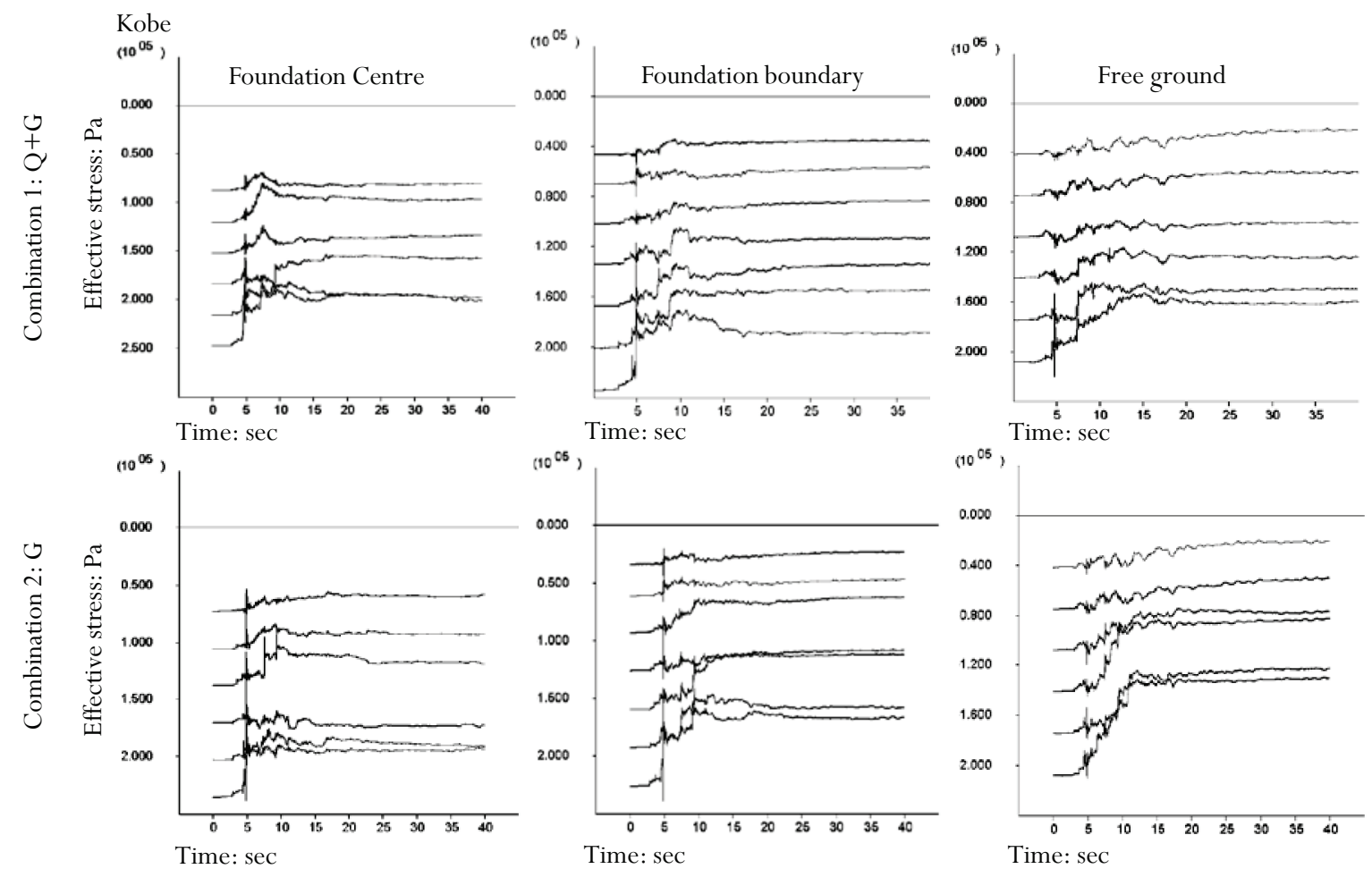

Fig. 5(b) Time history of effective stress - Kobe scenario 


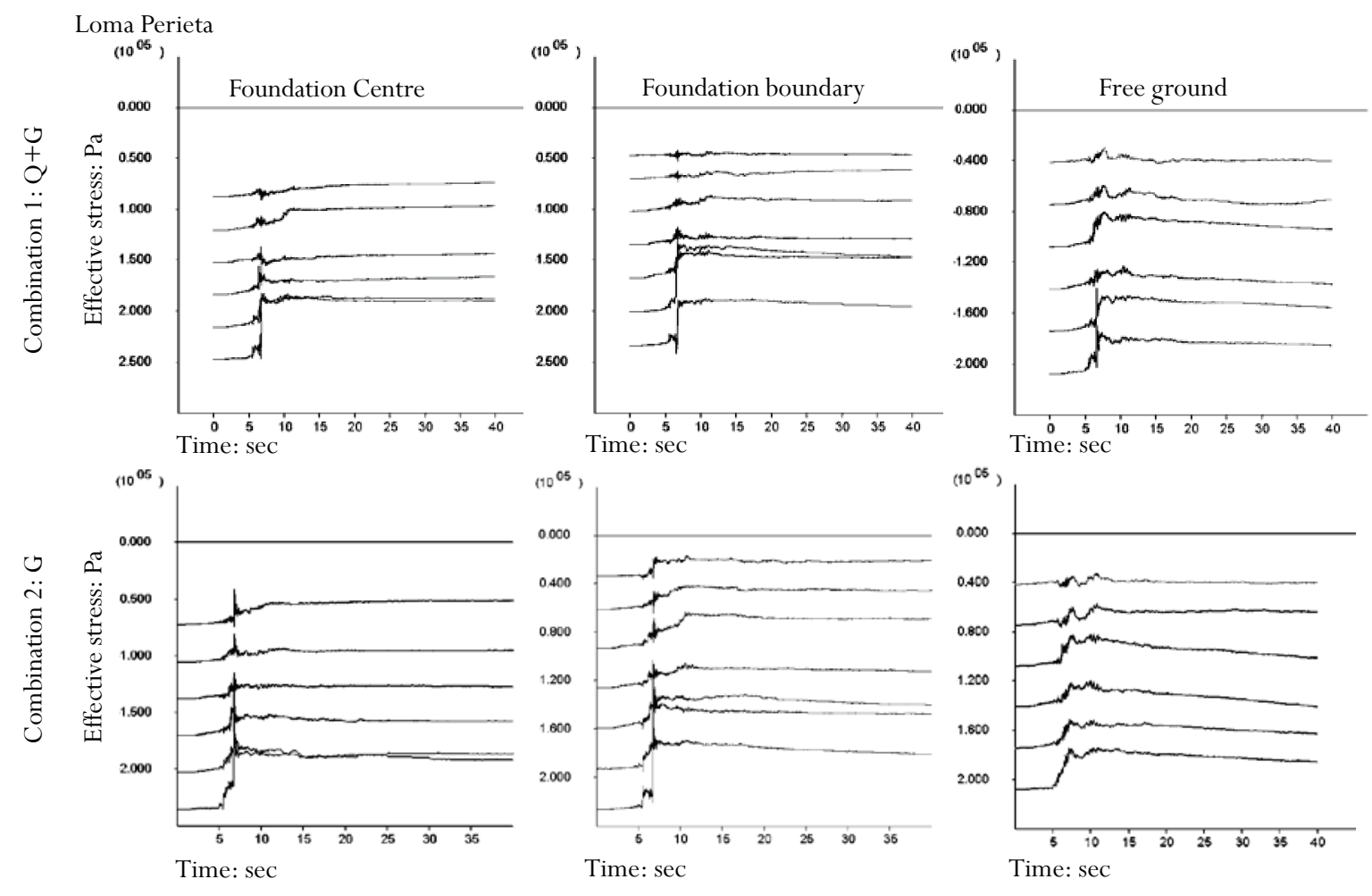

Fig. 5(c) Time history of effective stress - Lona Perieta scenario
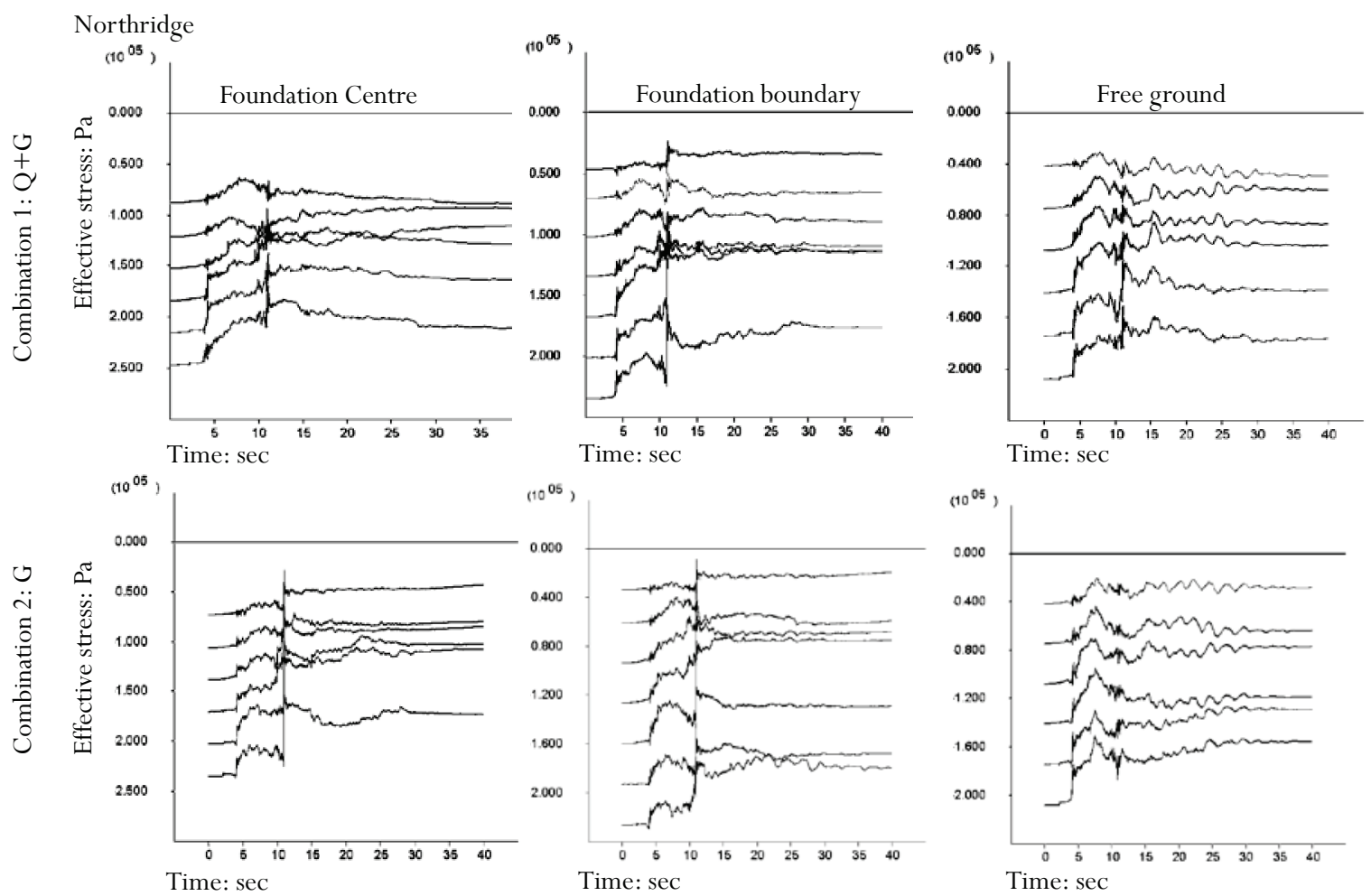

Fig. 5(d) Time history of effective stress - Northridge scenario 

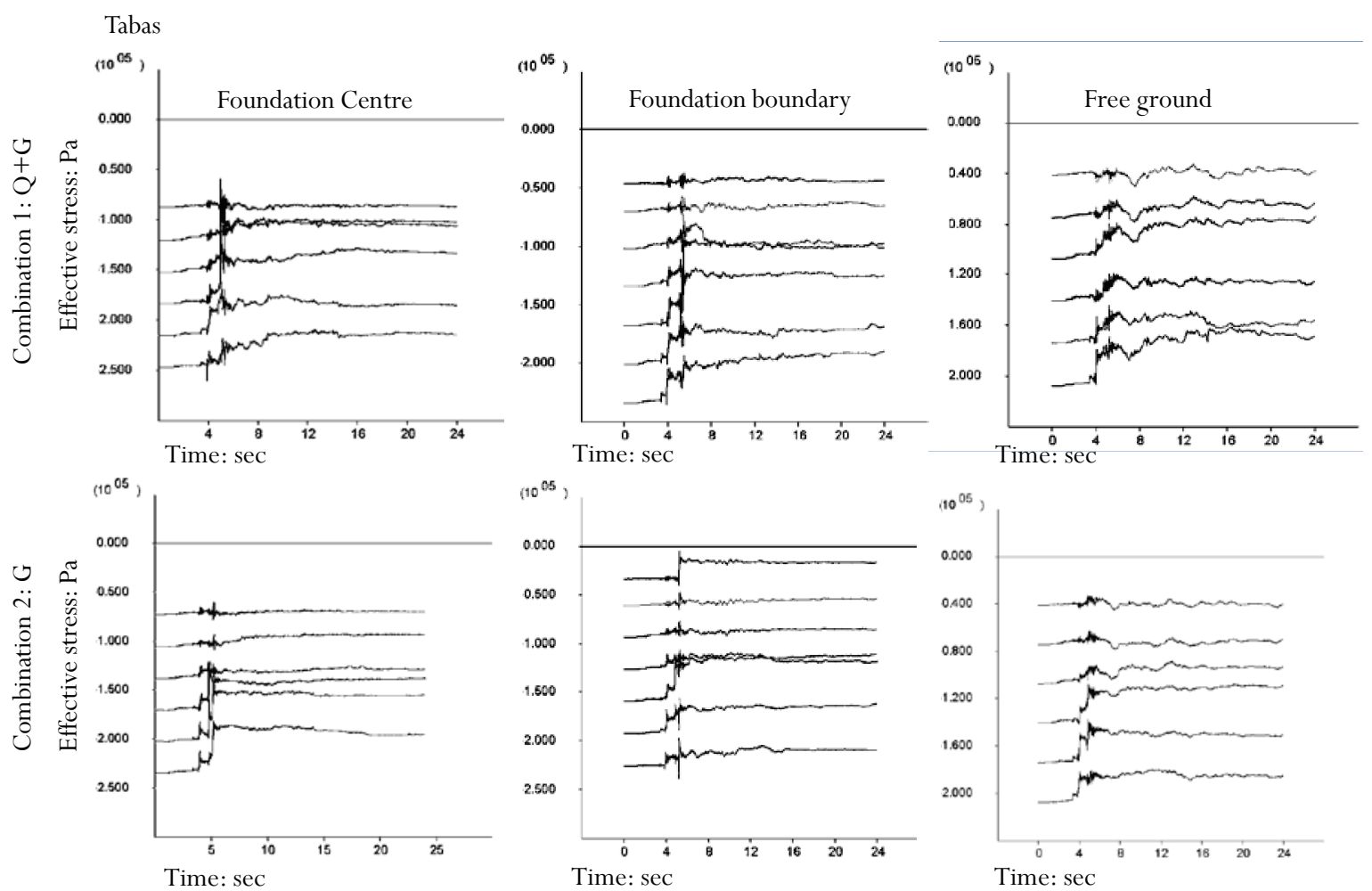

Fig. 5(e) Time history of effective stress - Tabas scenario

A suite of observations are made through examining the timed effective stress trends (Fig. 5) for the six input motions: Upon seismic excitation of shallow foundations, the likelihood of the loss in effective stress is found to be greater in deeper depths. For surcharged areas, the loss in effective stress terminates as the amplitude decreases from its early maximum order. For free field, however, the loss in effective stress continues irrespective of the magnitude of the motion amplitude.

In Fig. 6 and Fig 7, the pore pressure is plotted against the depth for both loading combinations. An $r_{u}=0.7$ is set as the threshold for liquefaction. The relatively lower residual pore pressure ratio captured immediately beneath the foundation is in agreement with the work of Andrianopoulos et al. (2006). The analysis suggests a reduction in $r_{u}$ for regions within the influence zone of bearing pressure. Risk of liquefaction decreased with an increase in surcharge pressure (combination $1 \mathrm{G}+\mathrm{Q}$ ) and for points closer to the centreline of the foundation (Fig 4a comparing with Fig 3b). This is generally in agreement with recent findings of Bertalot et al. (2013), which was predominantly based on collated field data. Findings at this stage may suggest the use of spread foundations with a fairly good degree of certainty should the ultimate and serviceability limit states are satisfied. 

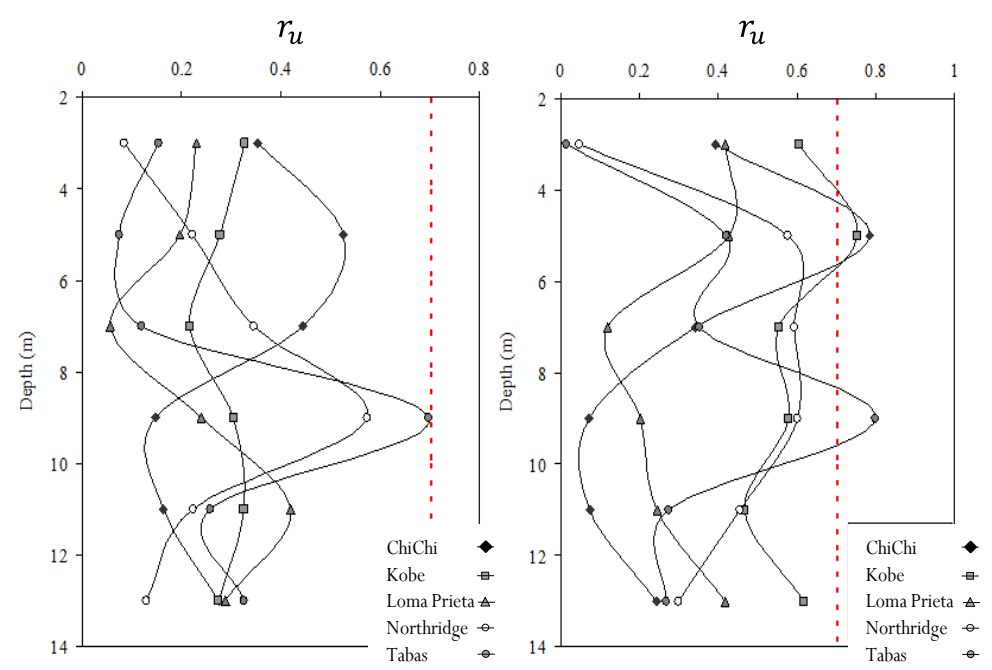

Fig. 6 Pore pressure ratio - Combination $1 \mathrm{G}+\mathrm{Q}$ : dashed line indicating liquefaction risk threshold (a-left) free ground (b-right) beneath foundation edge $r_{u}$
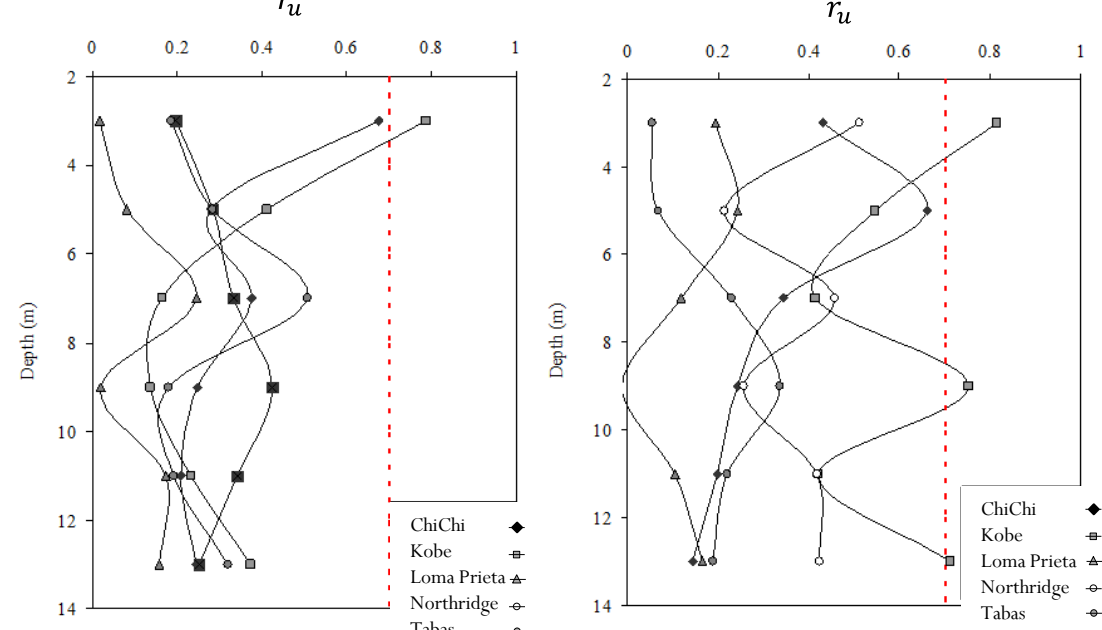

Fig. 7 Pore pressure ratio - Beneath the centreline of foundation: dashed line indicating liquefaction risk threshold (a-left) Combination $1 \mathrm{G}+\mathrm{Q}$ (b-right) Combination $2 \mathrm{G}+0$

A total number of 41 'type A' piles combined with 19 'type B' piles were initially recommended to mitigate the risk of liquefaction. Piles were designed to act as single elements and were designed to be capped with an $80 \mathrm{~cm}$ thick slab of c.840 $\mathrm{m}^{2}$ area (Fig. 8). Through non-linear dynamic analysis, surcharge is deemed to reduce the liquefaction potential, whereby soil beneath the structure shows admissible levels of risk for amplitudes of horizontal input sine waves of $300 \mathrm{gal}, \mathrm{a}_{\max }=0.3 \mathrm{~g}$ with a frequency of $5 \mathrm{~Hz}$. Thereby, a 1m thick mat foundation with four layers of Fi20@20cm c/c could replace the designed piled system and satisfy state limits (predicted lateral and vertical displacements edging below $30 \mathrm{~mm}$ ).

The consequent reduction in carbon footprint is quantified using BS EN 15804 (2013), indicating that the alteration could contribute to embodied carbon emission limitation at a rate of $0.91 \mathrm{KgCO}_{2} \mathrm{e} / \mathrm{kg}$ for reinforcing steel combined with $0.17 \mathrm{kgCO}_{2} \mathrm{e} / \mathrm{kg}$ for $\mathrm{C} 50$ concrete. 


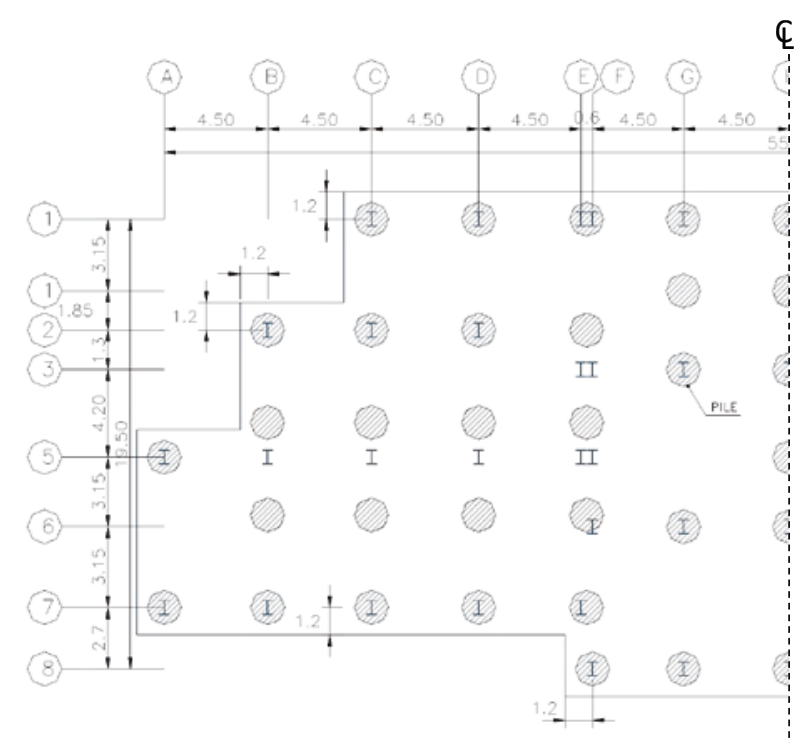

Piled foundation

Cap

$\begin{array}{ll}\text { Thickness: } \mathrm{m} & 0.8 \\ \text { Rebar } & \text { Fi25@25cm c/c x4 } \\ \text { Tai bar } & \text { Fi10@20cm c/c x2 }\end{array}$

Pile 'A'

Length: $m \quad 15.0$

Diameter: $\mathrm{m} \quad 1.5$

Rebar 28Fi20

Pile 'B'

Spiral bar $\quad$ Fi10@15cm c/c

Length: $\mathrm{m} \quad 15.0$

Diameter: $\mathrm{m} \quad 2.0$

Rebar $\quad 16$ Fi20

Spiral bar $\quad$ Fi10@15cm c/c

Fig 8. Layout of piled foundation: dark hatched circles represent type 'B' piles while blue hatched circles represent type 'A' piles

For a reduced workforce (and bus roundtrips), material (rebar, concrete, etc), energy (Diesel, network electricity), machines, and for similar freight distance, road type, mobilization and demobilization ratio $(0.3 \%)$ and waste ratio $(0.3 \%)$, the European Federation of Foundation Contractor (EFFC) and Deep Foundation Institute (DFI) methodology is used to compare the carbon footprint of the benchmark problem for piled and spread mat foundation types.

Fig. 9(a) and Fig. 9(b) show the carbon footprint of piled and spread foundations, respectively. The significant reduction in GHG from 1,400 to $460 \mathrm{tCO}_{2} \mathrm{e}$ is mainly associated with materials (a reduction from 1,157 to $392 \mathrm{tCO}_{2} \mathrm{e}$ ) and freight (from 161 to $46 \mathrm{tCO}_{2} \mathrm{e}$ ).

\begin{tabular}{|lr|}
\hline Materials & 1,200 tCO2e \\
\hline \multicolumn{2}{|c|}{ Concrete / Slurry/Grou 910 tCO2e } \\
\hline Steel & 180 tCO2e \\
\hline Other & 65 tCO2e \\
\hline Energy & $16 \mathrm{tCO} 2 \mathrm{e}$ \\
\hline Freight & $160 \mathrm{tCO} 2 \mathrm{e}$ \\
\hline Mob/demob & $4 \mathrm{tCO} 2 \mathrm{e}$ \\
\hline People's transportatio & $18 \mathrm{tCO} 2 \mathrm{e}$ \\
\hline Assets & $5 \mathrm{tCO} 2 \mathrm{e}$ \\
\hline Waste & $3 \mathrm{tCO} 2 \mathrm{e}$ \\
\hline
\end{tabular}
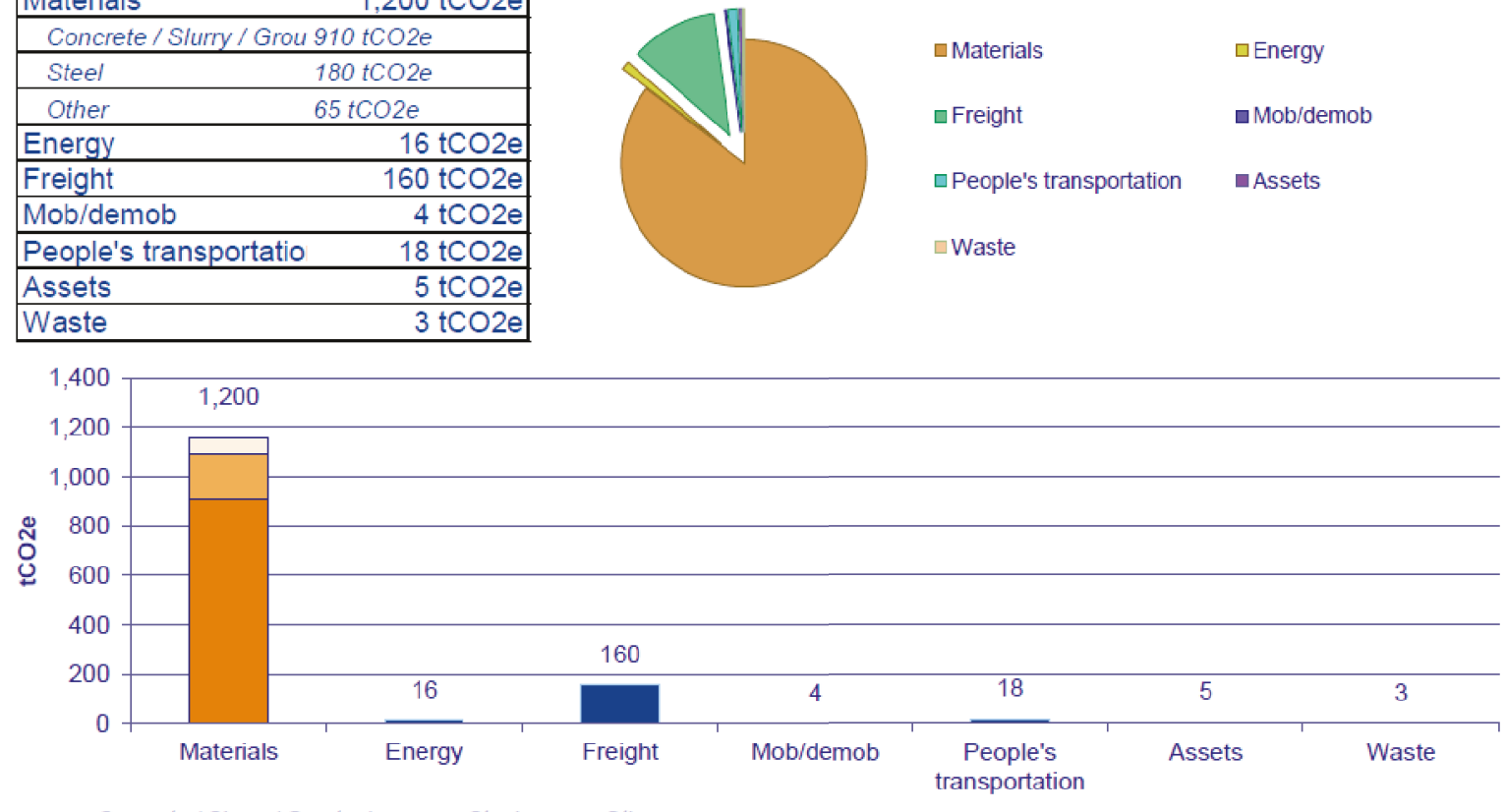

口Concrete / Slurry / Grout mix $\quad$ aSteel uOther

Fig. 9(a) Carbon footprint of benchmark problem for piled foundation adoption 


\begin{tabular}{|lr|}
\hline Materials & \multicolumn{2}{|c|}{$390 \mathrm{tCO} 2 \mathrm{e}$} \\
\hline \multicolumn{2}{|c|}{ Concrete / Slurry / Grou 280 $\mathrm{tCO} 2 \mathrm{e}$} \\
\hline Steel & $49 \mathrm{tCO} 2 \mathrm{e}$ \\
\hline Other & $65 \mathrm{tCO} 2 \mathrm{e}$ \\
\hline Energy & $12 \mathrm{tCO} 2 \mathrm{e}$ \\
\hline Freight & $46 \mathrm{tCO} 2 \mathrm{e}$ \\
\hline Mob/demob & $1 \mathrm{tCO} 2 \mathrm{e}$ \\
\hline People's transportatio & $11 \mathrm{tCO} 2 \mathrm{e}$ \\
\hline Assets & $2 \mathrm{tCO} 2 \mathrm{e}$ \\
\hline Waste & $1 \mathrm{tCO} 2 \mathrm{e}$ \\
\hline
\end{tabular}
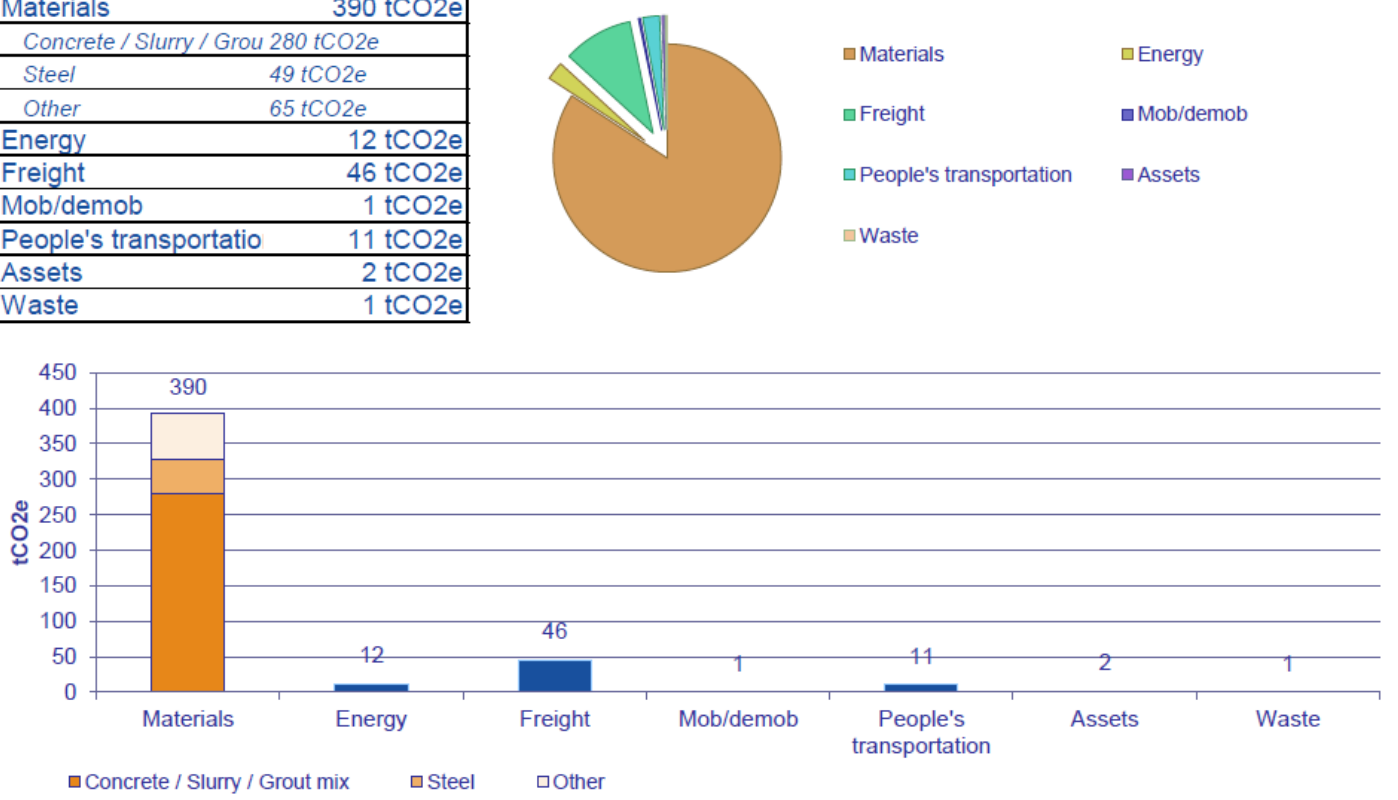

Fig. 9(b) Carbon footprint of benchmark problem for spread (mat) foundation adoption

\section{Conclusions}

Results of a seismic vulnerability survey of a benchmark 4-storey building on a liquefiable soil have been presented and critically discussed. The Finn strain-hardening plasticity model with non-associated flow rule is adopted to take into account the excess pore water pressure build-up on seismic excitation. Excess pore pressure measurements from a series of models suggested that, upon seismic excitation of shallow foundations, the likelihood of the loss of effective stress is greater in deeper depths and across free field. In addition, the likelihood of reaching a state of liquefaction is inversely proportional to foundation contact pressure. Beneath shallow foundations, the loss of effective stress terminates as the amplitude decreases from its early maximum order. For the surveyed benchmark problem, the commonly practiced risk assessment showed a moderate-to-high potential of liquefaction and the necessity for implementation of $900 \mathrm{~m}$ of drilling to cast $15 \mathrm{~m}$ long $1.5-2.0 \mathrm{~m}$ in diameter reinforced concrete piles. However, through taking into account the impact of dead surcharge in analysis and the Finn constitutive model, the original scheme was altered to a 1-m thick mat foundation. That alteration in design benefitted in a $75 \%$ drop in the emission rate, a marked proportion of which was on reduced materials and haulage carbon cost.

\section{Acknowledgements}

The benchmark project details were used with the permission of the owner, the National Rehabilitation and Retrofitting of Schools Organization - North East branch.

\section{List of Notations}

$R_{u} \quad$ Excess pore water pressure ratio

$K_{G}^{E} \quad$ Elastic shear modulus

$B^{E} \quad$ Elastic bulk modulus

$P_{a} \quad$ Atmospheric pressure

ne Coefficient between 0.4 to 0.6

$\phi_{c v} \quad$ Constant volume angle of friction

$N_{160} \quad$ Modified blow SPT number

$G_{i}^{p} \quad$ Plastic modulus at stress ratio $\eta$ tending to zero 


\begin{tabular}{ll}
\multicolumn{1}{c}{$\eta_{f}$} & Stress ratio at failure \\
$R_{f}$ & Coefficient between 0.7 to 0.98, inversely proportional with relative density \\
W & Water content \\
$\mathrm{E}_{\mathrm{d}}$ & Dynamic modulus of Elasticity \\
$\mathrm{E}_{\mathrm{s}}$ & Static modulus of Elasticity \\
$\mathrm{D}$ & Diameter of grains \\
$\mathrm{e}$ & Void ratio \\
$\varnothing$, & Peak drained angle of friction \\
$\mathrm{C}^{\prime}$ & Effective cohesion \\
$\gamma$ & Unit weight \\
$v$ & Poisson's ratio \\
$\varepsilon_{v}$ & Volumetric strain \\
$\tau$ & Shear stress \\
$\sigma^{\prime}$ & Effective normal stress \\
$\mathrm{mbgl}$ & Metre below ground level \\
$\mathrm{mAOD}$ & Metre above ordnance datum
\end{tabular}

\section{Reference}

Abate, G., Caruso, C., Massimino, M.R. and Maugeri, M. (2007) "Validation of a new soil constitutive model for cyclic loading by FEM analysis", in Ling, H., Callisto, L., Leshchinsky, D. and Koseki, J. (eds.) Soil StressStrain Behavior: Measurement, Modeling and Analysis. Springer Netherlands, 759-768.

Abate, G., Caruso, C., Massimino, M.R., Maugeri, M. (2008) "Evaluation of shallow foundation settlements by an elasto-plastic kinematic-isotropic hardening numerical model for granular soil". Geomechanics and Geoengineering, 3(1), 27-40.

Abate, G., Massimino, M.R., Maugeri, M., Wood, D.M. (2010). "Numerical modelling of a shaking table test for soil-foundation-superstructure interaction by means of a soil constitutive model implemented in a FEM code". Geotechnical and Geological Engineering, 28(1), 37-59.

Bertalot, D. and Brennan, A.J. (2015) "Influence of initial stress distribution on liquefaction-induced settlement of shallow foundations", Géotechnique, 65(5), 418-428.

Bertalot, D., Brennan, A.J. and Villalobos, F.A. (2013) "Influence of bearing pressure on liquefaction-induced settlement of shallow foundations", Géotechnique, 63(5), 391-399.

BS EN 15804+A1 (2013): Sustainability of construction works. Environmental product declarations. Core rules for the product category of construction products, British Standard, London.

Chian, S.C., Tokimatsu, K. and Madabhushi, S.P.G. (2014) "Soil liquefaction-induced uplift of underground structures: physical and numerical modeling", Journal of Geotechnical and Geoenvironmental Engineering, 140(10).

Ghosh, B. and Madabhushi, S.P.G. (2004) "Dynamic soil structure interaction for layered and inhomogeneous ground: a comparative study", 13th World Conference on Earthquake Engineering Vancouver, BC Canada. Hashemi, M., Nikoudel, M.R., Khamehchiyan, M. and Hafezi Moghadas, N. (2014) "Engineering geology and geohazards of Sefidrud delta, South Caspian coast', in Lollino, G., Manconi, A., Locat, J., Huang, Y. and Canals Artigas, M. (eds.) Engineering Geology for Society and Territory, 4, 77-83.

Hashemi, M., Nikoudel, M.R., Moghaddas, N.H. and Khamehchiyan, M. (2013) "Engineering geological assessment of the Anzali coastal region to sustain urban planning and development', in Huang, Y., Wu, F., Shi, Z. and Ye, B. (eds.) New Frontiers in Engineering Geology and the Environment, 135-140.

James, M., Aubertin, M., Wijewickreme, D. and Wilson, G.W. (2011) "A laboratory investigation of the dynamic properties of tailings", Canadian Geotechnical Journal, 48(11), 1587-1600.

Kuhlemeyer, R.L. and Lysmer, J. (1973) "Finite element method accuracy for wave propagation problems", Journal of Soil Mechanics and Foundations Division, 99(5), 421-427.

Majidi, A., Sharifi Soltani, A. and Litkouhi, S. (2007) "Mitigation of liquefaction hazard by dynamic compaction", Proceedings of the ICE Ground Improvement, 11(3), 137-143.

Martin, G.R., Seed, H.B. and Finn, W.D.L. (1975) "Fundamentals of liquefaction under cyclic loading', $A S C E$ Journal of the Geotechnical Engineering Division, 101(5), 423-438.

Maugeri, M., Abate, G., Massimino, M.R. (2012). "Soil-Structure Interaction for Seismic Improvement of Noto Cathedral (Italy)". Special Topics in Earthquake Geotechnical Engineering in Geotechnical. Sakr M.A., Ansal A. (eds.). Geotechnical, Geological and Earthquake Engineering Series, 16(2012), 217-239. 
Naeini, S.A. and Gholampoor, N. (2014) "Cyclic behaviour of dry silty sand reinforced with a geotextile", Geotextiles and Geomembranes, 42(6), 611-619.

Romeo, R.W., Amoroso, S., Facciorusso, J., Lenti, L., Madiai, C., Martino, S., Monaco, P., Rinaldis, D. and Totani, F. (2015) "Soil liquefaction during the Emilia, 2012 seismic sequence: investigation and analysis", Engineering Geology for Society and Territory, 5. 1107-1110.

Sawicki, A. and Mierczyński, J. (2015) "Discussion of soil liquefaction-induced uplift of underground structures: physical and numerical modeling" by Siau Chen Chian, Kohji Tokimatsu, and Santana Phani Gopal Madabhushi, Journal of Geotechnical and Geoenvironmental Engineering, 141(9).

Seed, H.B. (1987) "Design problems in soil liquefaction", Journal of Geotechnical Engineering, 113(8), 827845.

Simpson, C. (2013) "F12: Farming Wind Energy", RenewableUK 2013. Birmingham, UK.

Steedman, R.S., Ledbetter, R.H. and Hynes, M.E. (2000) Soil dynamics and liquefaction, American Society of Civil Engineers, Geotechnical Special Publication, Denver, USA.

Wang, G., Lan, H. and Yu, G. (2013) "Challenges and recent advances in geotechnical and seismic research and practices", Proceedings of the $2^{\text {nd }}$ International Conference on Geotechnical and Earthquake Engineering, Chengdu, China, October.

Wichtmann, T., Niemunis, A. and Triantafyllidis, T. (2004) "Strain accumulation in sand due to drained uniaxial cyclic loading", in Triantafyllidis, T. (ed.) Cyclic behaviour of soils and liquefaction phenomena. Taylor \& Francis Group, London, UK.

Youd, T.L., Idriss, I.M., Andrus, R.D., Arango, I., Castro, G., Christian, J.T., Dobry, R., Finn, W.D.L., Leslie, F., Ishihara, K., Koester, J.P., Liao, S.S.C., Marcuson, W.F.I., Moriwaki, Y., Power, M.S., Robertson, P.K., Seed, R.B. and Stokoe, K.H.I. (2001) "Liquefaction resistance of soils: summary report from the 1996 NCEER and 1998 NCEER/NSF workshops on evaluation of liquefaction resistance of soils", Journal of Geotechnical and Geoenvironmental Engineering, 127(10), 817-833.

Zhang, W. and Goh, A.T.C (2016) "Evaluating seismic liquefaction potential using multivariate adaptive regression splines and logistic regression", Geomechanics and Engineering, 10(3). 269-284. 